\title{
The Demand Response Technology Cluster: Accelerating UK residential consumer engagement with time-of-use tariffs, electric vehicles and smart meters via digital comparison tools
}

\author{
R. Carmichael ${ }^{a, *}$, R. Gross ${ }^{a}$, R. Hanna ${ }^{a}$, A. Rhodes ${ }^{b}$, T. Green ${ }^{b}$ \\ ${ }^{\text {a } C e n t r e ~ f o r ~ E n v i r o n m e n t a l ~ P o l i c y, ~ W e e k s ~ B u i l d i n g, ~ 16-18 ~ P r i n c e ' s ~ G a r d e n s, ~ I m p e r i a l ~ C o l l e g e ~ L o n d o n, ~ S o u t h ~ K e n s i n g t o n, ~ L o n d o n, ~ S W 7 ~ 1 N E, ~ U K ~}$ \\ ${ }^{\mathrm{b}}$ Energy Futures Lab, Energy Futures Lab, Electrical and Electronic Engineering Building, Imperial College London, South Kensington, London, SW7 2AZ, UK
}

\section{A R T I C L E I N F O}

\section{Keywords:}

Residential demand response

Smart meters

Time-of-use electricity tariffs

Digital comparison tools/price comparison

websites

Electric vehicles

Technology cluster

\begin{abstract}
A B S T R A C T
Cost-effectively decarbonising the power sector and household energy use using variable renewable energy will require that electricity consumption becomes much more flexible and responsive to constraints in supply and the distribution network. In recent years residential demand response (DR) has received increasing attention that has sought to answer, based on current evidence, questions about how much consumers will engage with DR.

This paper critically reviews the evidence base for residential consumer engagement with DR and draws out several important limitations in it. We argue for a more action-oriented focus on developing practical strategies to enable and unlock greater loadshifting and consumer engagement with DR within a changing technology and regulatory context. A number of recommendations are put forward for accelerating UK consumer engagement with DR, presented under three broad strategies: (a) promote awareness of smart tariffs, smart meters and storage and automation behind-the-meter devices as mutually-supportive components within a common 'DR technology cluster'; (b) deliver targeted support for adoption of electric vehicles and other storage and automation technologies; (c) enable and support informed adoption of DR-enabling products and services through 'smarter' digital comparison tools (DCTs), data portability, and faster, simpler switching.

The interdependency between components within this DR technology cluster delivers efficiency but also poses a risk that one delayed component (e.g., smart metering) will hold-up policy and industry support for other components. The urgency of decarbonisation goals makes it necessary to push forward as many of these elements as possible rather than the pace being set by the slowest.
\end{abstract}

\section{Introduction}

A number of national governments have now set, or are proposing, binding targets for net zero emissions [1]. Reaching net zero ambitions will require greater efforts across all sectors and much greater involvement of households. Most of the action needed to meet the UK net-zero target will require some behavioural or societal changes [2]. On the global level, household consumption, including indirect emissions, accounts for an estimated $72 \%$ of greenhouse gas emissions [3,4]. Within high-income European countries, household consumption footprints are dominated by car and plane mobility, meat and dairy consumption, and heating [5]. Within these countries, ambitious decarbonisation of the power sector ${ }^{1}$ combined with the electrification of car mobility and of domestic heating offer opportunities for deep reductions in typical household carbon footprints. The changes required and the viability of alternatives will depend to some degree upon local contexts but it is widely considered that flexibility in residential electricity consumption (demand response, or ' $\mathrm{DR}$ ') ) will have a major role to play in smart energy systems for low-carbon electricity, transport and heat [6,7].

It is proposed here that research and analysis of residential consumer engagement with DR continues to be driven too much by the availability of evidence rather than the questions that need answering and the delivery of solutions. This paper further argues that unlocking greater residential DR requires an understanding of what enables and constrains DR engagement in specific contexts - including patterns of energy supply

\footnotetext{
* Corresponding author. Centre for Environmental Policy, Imperial College London, 16-18 Prince's Gardens, South Kensington, London, SW7 1NE, UK. E-mail addresses: r.carmichael@imperial.ac.uk (R. Carmichael), robert.gross@imperial.ac.uk (R. Gross), r.hanna@imperial.ac.uk (R. Hanna), aidan.rhodes@ imperial.ac.uk (A. Rhodes), t.green@imperial.ac.uk (T. Green).

${ }^{1}$ Industry involved in the production and distribution of electricity.

2 Demand Response (sometimes demand side response, DSR) is flexibility on the consumption side and contrasts with the traditional supply-follows-demand model.
} 


\author{
Abbreviations/glossary \\ CAD Consumer Access Device \\ DCC Data Communications Company \\ DCT Digital Comparison Tool \\ DLC Direct Load Control \\ DR Demand Response \\ Dynamic TOU Dynamic time-of-use tariff (time-varying pricing \\ where rate changes do not occur at set times; consumers \\ are typically notified in advance) \\ EV Electric vehicle \\ FIT Feed-in-tariff for exporting self-generated power to the \\ grid \\ GB Great Britain \\ LCL Low Carbon London (dynamic TOU tariff trial) \\ MHHS Market-wide half-hourly settlement \\ PCW Price comparison website \\ PEV Plug-in electric vehicle \\ SEG Smart export guarantee (SEG), the successor to the FIT \\ in the UK \\ Smart tariff Time-varying electricity tariff requiring a smart \\ meter \\ SMETS1 First generation smart meter \\ SMETS2 Second generation smart meter \\ SMIP Smart Meter Implementation Programme \\ Static TOU A time-of-use (TOU) tariff on which electricity is \\ priced at different rates at fixed times of the day or \\ week, e.g., high-rate during evening peak hours of \\ $5-8 \mathrm{pm}$ and low-rate overnight \\ TOU Time-of-use (electricity tariff)
}

and demand, infrastructure, regulation, markets, consumer attitudes and barriers to adoption. The importance of context for research and for how change is achieved is recognised and promoted by work that takes an action-oriented and 'second order science' approach to facilitating energy transitions [8]. Consistent with this approach this review paper therefore surveys the evidence base for consumer engagement with DR and also considers opportunities for delivering deep reductions in household emissions within the UK context through greater residential consumer engagement with demand response and related technologies.

\subsection{The value of residential demand response in the UK}

Within the UK power sector, the Clean Growth Strategy [9] aims for a high renewables and flexibility approach to a low carbon energy system which is also secure, affordable and efficient. Large and rapid expansion of renewable energy is envisaged from offshore and onshore wind, and later solar photovoltaics (PV), driven by both the need to shift to low-carbon generation and by growth in household demand arising from the electrification of transport and heating $[10,11]$. Current scenarios for decarbonising UK residential heat incorporate a mix of district heating, utilisation of the gas grid for biogas and hydrogen, and electrification via heat pump technology $[10,12,13]$. Increasing electrification of both vehicles and, to some degree, domestic heating forms an important background to the focus of this paper.

The challenge to balance fluctuating supply and demand, and to defer reinforcement of an ageing transmission and distribution network, confers significant value on sources of flexibility [14]. This value could be as much as $£ 8$ billion per year in the UK in a smart energy system with high levels of variable renewables and inflexible nuclear generation [15, 16]. A number of options exist for system balancing including grid interconnection, flexible generation, storage, demand side management and demand response [17]. Even before new loads from vehicles and heating, residential electricity consumption makes up around 35\% of total UK electricity consumption [18] and the aggregated flexibility from households is now envisaged as having the potential to provide significant system flexibility [19]. Residential flexibility in demand - or demand response (DR) - is anticipated to be delivered via a range of cost-reflective time-varying electricity pricing options that reward household flexibility. In recent years residential DR has received growing attention, arising within the context of UK Government decarbonisation ambitions and opportunities for rapid technological change supporting smart and flexible power $[9,19]$. Demand response is also part of the business case for smart meters: in its cost-benefit analysis of the Smart Metering Implementation Programme (SMIP) the UK Government assumed that, by $2020,20 \%$ of consumers will switch to static time-of-use (TOU) electricity tariffs (which apply different rates at fixed time periods such as a higher rate during the evening peak-time), rising to $30 \%$ in 2030 [20].

\subsection{Evidence reviews, the streetlight effect and action-oriented research}

There remains, however, considerable uncertainty around realising the potential of residential DR [e.g., 15,21]. Consumer engagement with demand response will be key for consumers to voluntarily adopt services and technologies (including smart meters and smart tariffs), which are not mandatory, and consume electricity much more flexibly. A number of reviews of the evidence base for household engagement with DR have been carried out to assess its feasibility and implications for consumers [21-26]. These reviews report typically modest savings on trials and sometimes cast doubt on more optimistic projections of engagement produced by work that models demand response [21].

A shift in focus for DR engagement research has been suggested some time ago: a "move away from 'Will consumers participate?' to 'How do we maximise participation?'” (p.72) [27]. It would be productive to focus more on future opportunities, overcoming barriers and enabling greater engagement and responsiveness. To continue to be relevant and useful in this way, the academic literature on household flexibility must attend to the evolving technology and regulatory context. Two important features in this changing landscape for household DR are smart metering and electric vehicles (EVs) for which, as with DR, there is much discussion over targets, uncertainties and challenges for consumer engagement and adoption. This review paper surveys the evidence within the academic and grey literature on household engagement with DR but focusses on the barriers, drivers and opportunities for greater engagement, participation and impact.

We show that the systematic evidence reviews aiming to estimate and predict future levels of DR consumer engagement are of limited practical value going forward due to limitations of the data and a rapidly evolving context. Notable in this regard is reliance on data from DR pilots without automation and storage devices and on surveys of tariff preferences which do not address the lack of support for smart tariff comparison. For the UK at least, continuing to review the existing evidence would reflect the observational bias known as the 'streetlight effect'. This refers to a cautionary tale of a drunkard looking for a lost house key under a streetlight, where it is easy to see, despite him knowing that he dropped his key on the other, darker, side of the street. Used in an academic context since Kaplan [28], it is "the tendency for researchers to focus on particular questions, cases and variables for reasons of convenience or data availability rather than broader relevance, policy import, or construct validity" (p.137) [29] and reflects a preference for methodological security over a willingness to search for answers where they are most likely to be found [30]. This point is echoed in Fazey et al.'s [8] recommendation that research on energy transitions be framed more closely by the "needs of society (i.e. social or environmental improvement)" (p.58) than by the needs of research. They advocate research on energy transitions that is "more purposive, participatory, action-oriented, [and] dominated by pragmatism" (Ibid, p.58) and argue that "greater focus is needed on learning how to make 
change happen" (p.54). In the context of an urgent need to decarbonise, analyses based on the current evidence base for DR engagement risk contributing to inertia rather than change.

This paper is an attempt to take a more action-oriented and solutionsfocussed approach. It makes a contribution to the literature on residential consumer engagement with time-varying electricity pricing and DR-enabling technologies such as smart meters and electric vehicles. The UK is used as a case study for policy recommendations which could be applied in other countries and regions that are moving towards smart, flexible energy systems.

The evidence review methodology used is described in Section 2. In Section 3, we draw out some important limitations to the evidence base, primarily with reference to the UK, and propose a renewed focus on actions to unlock greater levels of DR engagement. Section 4 makes several recommendations for concrete actions by regulators and policymakers for residential DR in the UK context.

\section{Methodology}

A systematic review methodology [31,32] was used to collect and evaluate the evidence base on residential consumer engagement with DR services and technologies. We draw on findings, both within the UK and beyond, from trials and pilot schemes of TOU tariffs and other DR services as well as survey data and several previous evidence reviews in the area.

Evidence was largely identified through searches of two databases: Elsevier Science Direct, for academic literature, and Google, as a first step in identifying grey literature. Additional searches were carried out on specific websites hosting relevant material. For further detail of inclusion and exclusion criteria and search protocols see Appendix. A small number of interviews were also conducted with selected experts from academia, industry, regulation and government.

Shipworth, Fell and Elam [33] point to the value of grey literature for providing important contextual information within systematic evidence reviews. Grey literature on energy reflects a range of stakeholder perspectives - including industry, consumers and regulators - and is especially valuable if evidence reviews are to make constructive contributions. Shipworth et al. (ibid.) also point to the difficulty of systematically identifying grey literature but we found following citation trails ${ }^{3}$ to be valuable, particularly for identifying highly relevant publications. Citation trails (or 'snowballing' [34]) deserves greater recognition as a supplement to database searches in systematic reviews.

\section{The evidence base for household engagement with demand response - findings and limitations}

The following discussion draws out the main insights from a critical review of the evidence base, from within and beyond the UK, on residential consumer engagement with DR. For a longer discussion see Carmichael, Gross and Rhodes [35]. Consumer engagement with DR has previously been characterised as occurring in three stages - participation, performance, and persistence [22,36]. A similar inclusive framing of engagement will be used here, though less based on linear stages and with greater focus on technology adoption than is typical.

\subsection{Adoption rates and tariff preferences: from stated preferences to switching behaviours}

'Participation' in DR includes recruitment onto trials, take-up of tariffs and acceptance. Evidence about consumer acceptance and uptake of DR offerings comes from data on recruitment in pilots and trials of DR services as well as surveys collecting consumers' reported interest in, or

\footnotetext{
${ }^{3}$ I.e. finding other documents that are cited in, or that cite, a publication already being reviewed.
}

'stated preferences' for, various types of DR offerings.

\subsubsection{Recruitment methods and tariff preferences}

One of the most robust findings on consumer participation in DR is that a far larger proportion of households are enrolled when households must opt-out than when participants are asked to opt-in Refs. [22,23]. However, the total or aggregate DR delivered by all participating households does not directly scale-up because many households enrolled through opt-out recruitment show little engagement in terms of responsiveness (ibid.).

The evidence on consumer preferences for types of demand response is mixed. A survey of GB bill-payers [23] found a moderate preference for static TOU rather than dynamic TOU tariffs - also reported by Sustainability First \& CSE [37] and Chase et al. [22] - but no other differences in tariff design influenced stated interest. In contrast, Fell et al. [38] reported Direct Load Control (DLC) to be the most popular type of DR but a survey conducted with bill-payers previously participating in the Low Carbon London (LCL) dynamic TOU trial found that DLC was the least popular option and no difference in stated preferences was observed between static TOU and dynamic TOU [24]. Drawing again on UK survey data, Fell [39] found that bill-payers' reported interest in TOU tariffs increased with their perceived 'ease of use' and opportunity to save money but concludes that the most important predictor of acceptance for all DR tariffs and services was trust in suppliers.

\subsubsection{Developmental aspects to adoption: a familiarity effect and ladder of engagement?}

Very little reliable data is available on persistence of DR responsiveness (also reported by Chase et al. [22]). For TOU tariff pilots the reasons include the finite nature of a typical 12-month trial and the failure to collect baseline consumption data before and after the DR trial period. Due to the very early stage of smart tariffs (TOU tariffs requiring a smart meter) in the market, even less real-world data is available on customer loyalty and churn rates for smart TOU tariffs.

However, there is evidence that participants in TOU trials tend to assess these tariffs positively and report a high degree of satisfaction. A review of sixteen TOU field trials, mostly in the US, concluded that experience of being on a TOU tariff was positively evaluated [23]. Of the UK households who participated in the day-ahead dynamic TOU tariff in the Low Carbon London (LCL) project, $77 \%$ of respondents $(n=708)$ indicated they would have liked to stay on the tariff [40]. Although recruitment on the LCL trial was opt-in, it was incentivised (including a guarantee of being reimbursed if financially worse off) which should have reduced sampling bias; survey responses were also incentivised to limit non-response bias. Both this survey and a later survey with households who participated in the LCL trial [24] showed much greater levels of interest in signing-up for smart TOU tariffs than found in Fell et al. [38]. Willingness to switch to a smart TOU tariff has also been found to be greater among consumers on Economy 7 and Economy 10 dual-rate tariffs (so-called 'legacy TOU tariffs' [41]) than other households [38].

Together, this discrepancy between reported interest in TOU among households with and without experience of TOU tariffs suggests a 'familiarity breeds consent' effect in consumer attitudes to smart TOU. In a similar vein, residents of a smart home were found to be more open to dynamic pricing [42]. Some possible reasons for this effect emerged in the LCL trial analysis which found that a majority of survey respondents reported experiencing positive aspects to the tariff: the tariff motivated them to get household chores (e.g., laundry, hoovering, ironing) done (80\%); was useful for planning and remembering activities (77\%); gave them a greater sense of control over energy bills (71\%); helped them reduce overall electricity consumption (63\%); and was in some ways enjoyable (55\%) [40] - though some of these may be unique to dynamic pricing tariff designs.

If first-hand experience with TOU/DR leads to greater acceptance, there could be potential for consumers to naturally follow, or be guided 
along, a 'ladder of engagement' - from initially simpler and/or lowerrisk time-varying tariff designs to DR services with greater complexity and/or greater price volatility [35], perhaps with greater support from DR-enabling technology. Alongside a developmental path for households, a societal developmental path for DR is likely to also play a role, as norms shift and support the diffusion of innovation [43], however, pilots, trials and surveys are not able to provide evidence of this.

If interest in, acceptance of, and liking for TOU grows after experience of living with DR offerings then stated preference methods conducted with samples representative of UK bill-payers, but with no firsthand experience of DR offerings, will tend to yield findings which underestimate the potential for engagement especially over the longerterm. In the future, household behaviours around switching to smart TOU and other DR offerings (their 'revealed preferences') may well exceed current stated preferences due to engagement growing with familiarity and improvements in the context for real world tariff-switching decisions.

Some research suggests strong interest already in smart tariffs. In survey research for Smart Energy GB, eighty per cent of UK householders with a smart meter said they would like to receive cheaper energy for using appliances at different times of the day [44]. Nicholson et al. [26] rightly recognise that surveys are insufficient for predicting future TOU tariff adoption rates and draw attention to the important point that the median figure for reported willingness to switch to a TOU tariff is five times higher than the median enrolment rate in TOU tariffs offered in the market. Barriers to adoption need to be addressed if this gap between reported interest and behaviours is to be closed. This will require taking a closer look at specific contexts for energy consumer engagement and switching behaviours. The context for UK consumers will be used here.

\subsubsection{UK switching habits and supports}

Participation in DR services will require customers to switch from their current tariff to a DR offering, and perhaps to another supplier. The UK regulator, Ofgem, has encouraged switching as the main route to residential energy consumer engagement and a more competitive market [45]. But it has been suggested that switching has worked for the benefit of switchers at the expense of non-switchers or those who switch infrequently [46]. Many households who do switch are repeat switchers but fifty-six per cent of bill-payers report that they have never switched supplier or were not sure if they had done so [47], suggesting perhaps that most may not participate in new DR offerings either. However, there are signs that take-up of smart TOU tariffs could potentially be better.

Firstly, eighty-two per cent of non-switchers report that they "would do so [switch] to save money" (p.46) [48]. This suggests that considerable scope exists to disrupt the patterns of switching habits observed to date if offerings have credible potential for savings. Reviews of pilots and surveys indicate that financial savings are the primary motivation for enrolling and remaining in smart TOU services [22,23] and a recent UK survey for Smart Energy GB found that reducing bills was the most appealing benefit of TOU tariffs [49].

Reasons given for not switching tariffs include uncertainty about the new supplier being cheaper than their previous supplier in a few months' time $[24,48,50]$, fuelled in part by pricing strategies characterised as 'tease and squeeze' [51] or 'bargain-then-rip-off' [50]. Such a lack of belief in tariff differences discourages participation in energy markets [52]. TOU and other DR offerings may be seen by customers as offering more credible potential for genuine savings: consumer scepticism about getting 'something for nothing' should be reduced with greater understanding that the flexibility they provide is valuable to the system and to suppliers.

3.1.3.1. Price comparison websites. Consumers' interest in financial savings when switching tariffs underlines the role of online price comparison services. Reliance on digital comparison tools (DCTs) is an important feature of UK switching behaviour relevant to DR uptake. Sixty-seven per cent of bill-payers looking for energy deals had used DCTs in the past year [53] and half of households who actually switched reported using a third party service - mainly price comparison websites (PCWs) [48] - up markedly from thirty-nine per cent in 2014 [54]. Users of DCTs generally found them easy to use and $96 \%$ were very or fairly satisfied with the experience [55]. Ofgem acknowledge an important role for the advice and guidance available through third party intermediaries (TPIs) such as PCWs, especially since the removal of the Tariff Comparison Rate (TCR) from the Clearer Information tools following the Retail Market Review (RMR) reform package [56]. The value of independent market comparison is further underlined by the finding that UK consumers' trust in energy firms is the lowest of all market sectors, below that even of banks [57]. DCTs reduce the 'information overload' of calculating future energy costs from consumption and tariff designs (electricity unit costs and standing charges etc). Digital comparison tools also reduce the 'choice overload' of comparing a wide range of suppliers and tariff options. Consumers tend to defer and procrastinate when faced with information and choice overload [58,59].

A further limitation with using stated preference methods to gauge future uptake of smart TOU tariffs (e.g. Ref. [38]) is that the research protocols used do not allow respondents access to DCTs. In the retail market consumers typically rely on PCWs to make switching decisions about relatively simple flat rate tariffs. Projecting bill impacts for TOU is much more complicated and uncertain. This suggests that consumers contemplating TOU tariffs would be likely to rely on appropriate DCTs were they to be available. However, the smart TOU tariffs now being offered in the UK are not included in the market comparisons provided by PCWs, nor are comparison services for TOU tariffs available to households in other European markets [60].

Stated preference methods have, to some degree, lacked 'mundane realism' - the extent to which events occurring in the research setting are likely to occur in the normal course of the participants' lives [61]. Real switching decisions may be influenced by: supplier marketing; discussion with household members; and seeing how other consumers behave, especially for innovative services for which visible of adoption by others is associated with more rapid uptake [43]. By studying consumers' reported interest in TOU without access to digital comparison tools, stated preference methods may reflect an existing reality but have also reproduced current market conditions which fail to enable consumers to make informed decisions about smart tariff adoption.

3.1.3.2. Smart meter rollout. A further barrier to switching is consumer concern about aspects of the price comparison and switching processes themselves. Sixty-seven per cent of respondents to a survey carried out for Ofgem mentioned concerns over some form of risk associated with switching (such as wrong meter readings being used) and less than half found it easy to compare tariffs [48]. Perceived overall difficulty in changing suppliers also deters switching [62]. At present, to get an accurate quote for flat-rate tariffs on a PCW, customers need to find a non-estimated annual statement and manually input their consumption data into the tool, a process which is often time-consuming, confusing and imprecise, which deters comparison and switching [63-65]. The UK's Smart Meter Implementation Programme (SMIP) presents an opportunity to mitigate some of these perceived risks and concerns through more accurate and available billing data and much faster switching.

A fast, simple, trusted and user-friendly switching process is even more important for smart TOU tariffs in order to lower barriers to consumers trying these new offerings. Diffusion of innovation scholars have observed that 'trialability' of an innovation is associated with faster adoption [43]. In a small survey $(n=78)$ of UK bill-payers who had previously participated in a dynamic TOU trial, $87 \%$ of respondents indicated that being able to "instantly and easily switch back to your old tariff if you were not happy with it" would make a TOU tariff more attractive [24]. The data suggesting a 'familiarity effect' for TOU 
engagement further calls attention to the importance of lowering barriers to consumers gaining some first-hand experience with DR offerings.

Unfortunately, the SMIP is behind schedule ${ }^{4}$ and $70 \%$ of UK homes do not yet have a smart meter as of Q3 2019 [66]. The vast majority of those installed are first generation ('SMETS1') smart meters for which interoperability problems persist (about half of these lose smart functionality if a household switches supplier). While a technical remedy for interoperability has now been developed to enrol SMETS1 meters into the Data Communications Company's (DCC) secure network [67] (through which suppliers can access half-hourly consumption data) it will take some time to implement and to roll out second generation (SMETS2) meters to the remaining households. The delayed rollout is also holding-up the introduction of market-wide half-hourly settlement [68] and the growth in DR offerings from suppliers that this would inevitably usher in.

\subsection{Responsiveness: from manual DR to technology adoption}

The responsiveness of households on DR services is crucial to the system benefits generated and to the financial savings that the evidence base indicates is the primary motivation for consumers to enrol and remain in such services.

\subsubsection{Manual load shifting}

A robust finding from TOU trials is that responsiveness and bill impacts vary between trials and are highly dependent on the specific details of the DR offerings being tested, and on local and regional contexts [22]. Responsiveness also varies widely between households. Analysis for Ofgem of the distributional impacts of TOU tariffs [24], which used data from two large TOU trials in the UK, found that the vast majority of households made savings on fixed and dynamic TOU tariffs. But although there were differences between sociodemographic groups, the variation in impacts within each group was much larger than that between groups (ibid.).

It has been noted before that high price volatility will be important to unlock the full value of DR (e.g. Ref. [22]) - and larger savings for households - but it may chiefly do so through supporting the adoption of technologies with large and automated shiftable loads rather than incentivising manual load shifting. ${ }^{5}$ An international review of over 40 domestic pricing pilots including several in GB and Ireland found that, "price response increases with a stronger price signal though it increases at a diminishing rate, suggesting that consumers eventually run out of practical actions that can reduce peak demand" (p.44) [69]. However, this flattening-off of responsiveness with increasing price signals is based on trials which relied on flexibility in daily energy-related behaviours ('manual DR'). Electric vehicle charging offers large and flexible loads but, as noted by Parrish et al. [21], has been almost entirely absent from the pilots, trials and surveys within the evidence base for residential DR.

This plateauing of price responsiveness is likely to change if adoption of appliances with large flexible loads and/or automating technologies is included. EVs and other storage and automation technologies can deliver greater DR with more convenience, predictability and reliability than manual DR. As rewards for flexibility increase, these flexibilityenabling technologies would become more cost-effective and affordable, driving adoption and delivering one or more sizable and steep upturns in responsiveness, rather than the diminishing returns and single plateau based on evidence from manual DR.

\footnotetext{
${ }^{4}$ As of June 2020, Ofgem have stated "All suppliers must take all reasonable steps to roll out smart meters to their domestic and small non-domestic customers by 30 June 2021 (previously 31 December 2020).” [147].

${ }^{5}$ Load-shifting is moving consumption (electrical load) either to an earlier or later time than would have occurred without demand response.
}

\subsubsection{Electric vehicles}

As EV adoption grows, smart managed charging will be required to avoid the need to upgrade the distribution network and to enable greater decarbonisation of power through increased use of wind and other variable renewables. Smart EV-charging can also deliver savings for owners to drive consumer adoption of both EVs and smart electricity tariffs.

Left unmanaged, charging an electric vehicle (EV) would lead to roughly doubling a typical household's evening peak demand (based on a $3.5 \mathrm{~kW}$ Nissan Leaf) [70]. Indications exist that substantial savings in EV-charging costs are possible on TOU tariffs [71,72]. Early results from the first dynamic TOU tariff on the UK market reported that customers saved an average of $£ 45$ on their annual bill compared with the supplier's own fixed tariff but EV-owners saved on average $£ 132$, or $£ 338$ per year compared to a typical 'flat-rate' standard variable tariff (SVT) from other suppliers [73]. Another supplier calculates that a Nissan Leaf EV-owner with average mileage could save almost $30 \%$ - around $£ 350$ on their annual electricity bill on their three-rate (8/11/41p) tariff versus their standard variable tariff [49].

These savings are benchmarked against the cost of EV-charging on flat-rate tariffs and do not include potentially larger cost savings between EV-charging costs and spending on petrol/diesel for the same driving behaviour. Even on a flat-rate tariff, driving a typical EV costs approximately one quarter of the cost of driving a petrol car the same distance [74]. Taking an average UK household spend of $£ 34$ per week on car fuel [75] this suggests a saving of approximately $£ 100$ per month for a typical household. Bi-directional charging also presents further opportunities for EV batteries via vehicle-to-grid (V2G) balancing services, potentially delivering system savings double that from smart-charging of EVs [76] and offering substantial additional cost savings to EV owners [72].

Smart EV charging to optimise consumer savings and system benefits appears to be both technically feasible and acceptable to consumers. A Western Power Distribution impact assessment found that "smart charging is likely to have negligible impact on an EV driver's ability to drive as they wish" (p.3) [77] although uncertainty remains about how mandating managed charging might affect consumer acceptance and uptake of EVs [78]. The My Electric Avenue project, the largest network-related trial in the UK, found that the majority of consumers were comfortable with the technology being able to control their charging [70]. Consistent with this, Fell et al. [79] report that although dynamic TOU was the least appealing tariff design in their survey, having access to 'automated response' technology made dynamic TOU as acceptable as static TOU. A survey for Smart Energy GB indicated that one third of drivers stated they would be 'more likely to purchase an electric vehicle if they could programme it to charge automatically at home when energy is cheapest' [80]. While the literature on EV adoption discusses smart charging of EVs in terms of system benefits, consideration of the potential for savings from TOU tariffs and other demand response services to support EV adoption is typically not considered (e.g. Refs. [81,82]).

Equally, as EV adoption costs fall EVs could increasingly become the key driver for cost-conscious consumers to engage with smart tariffs and other DR offerings. The cost of lithium-ion battery packs has tumbled by $79 \%$ since 2010 [83] and is expected to fall a further $66 \%$ between 2017 and 2030 [11]. For some households, the cost-effectiveness of combining an EV or a home battery with a smart tariff, and/or other DR services, may be further increased by installing solar PV to allow self-generated electricity to be stored, peak rates further avoided, and revenue accrued through Smart Export Guarantee (SEG) tariffs now offered by suppliers in the UK following the end of the Feed-in-tariff (FIT) [84]. An analysis of near-term opportunities for growth in EV, battery and solar PV found that strong mutual benefits and reduced payback periods make these technologies even more disruptive together than in isolation [85].

Reducing the upfront cost barrier to EV ownership through a battery 
or vehicle leasing business model - such as offered by Renault [86] could prove to be attractive for consumers, and companies have begun to bundle EV-leasing with an EV smart tariff (e.g., www.octopusev.com). Similar leasing models and bundled offerings are emerging for combining PV, home batteries and smart tariffs (e.g., Powervault partnering with Green Energy, Tonik Energy and Octopus Energy [87]).

\subsubsection{Domestic heating}

As for EVs, the move towards the electrification of at least a portion of domestic heat also entails a need for flexibility and an opportunity for household savings and engagement. Heating and hot water for UK homes make up $25 \%$ of total UK energy [88] and $15 \%$ of UK greenhouse gas emissions [89]. Within UK homes, space heating and domestic hot water account for $80 \%$ of energy requirements [90]. This is largely provided by gas, with only $7 \%$ of households using electric heating [91]. Electric heat for space, water and showering already adds to morning and evening peak loads and electrification of heating using heat pumps could add greatly to this, though UK uptake has been low to date $[88,92]$ especially compared to other northern European countries [93]. However, flexible electric heating may offer opportunities for system savings even greater than from EVs [76].

The Freedom Project [94] in the UK, for example, has demonstrated that hybrid heating technology can deliver both reliable comfort to consumers and benefits for the electricity system. When combined with time-varying pricing of electricity, hybrid heat pump (HHP) running costs can be optimised through smart controls, which maximise reliance on cheap-rate electricity to preheat the home (or other thermal storage) and use the home's existing gas boiler when electricity prices are high such as during periods of supply or network constraint. In the longer-term, the gas grid and households' gas central heating systems could incorporate more green gas (biomethane) or be adapted for hydrogen gas. This can give the consumer some reassurance that HHPs with back-up gas heating can satisfy winter peak heat demand and are relatively future-proof. Solutions for smart flexible heat and consumer engagement are discussed further in Carmichael et al. [95].

\section{Unlocking greater household engagement with flexibility services and technologies}

The preceding section has argued that the existing evidence base and analysis for residential DR does not reflect important emerging opportunities for much greater consumer engagement. Conclusions have typically been drawn from pilots which have relied on manual response to price signals and have lacked automation and storage devices, while studies of stated preferences have reproduced rather than confronted barriers to informed adoption of DR market offerings. Greater interest, uptake and responsiveness could be delivered by combining timevarying pricing with storage and automation technologies that enable convenient load-shifting of large loads. Based on cost-effectiveness and current uptake this is likely to be EVs in the first instance, followed by heat pumps and other smart storage devices. Smart meter adoption will also be an important enabling factor. Greater focus is required on actions to reduce barriers to adoption of these components, both individually and collectively. To this end, in Section 4 of this paper we discuss in turn the following three inter-dependent recommendations:

i. Increase awareness that smart tariffs, smart meters, and storage and automation technologies are mutually-supportive elements of a 'technology cluster' for flexibility that delivers benefits for households, system and environment;

ii. Deliver targeted support for adoption of DR-enabling technologies including smart storage and automation technologies such as EVs;

iii. Enable and support informed adoption decisions for flexibility products and services through smarter digital comparison tools and an improved switching process.

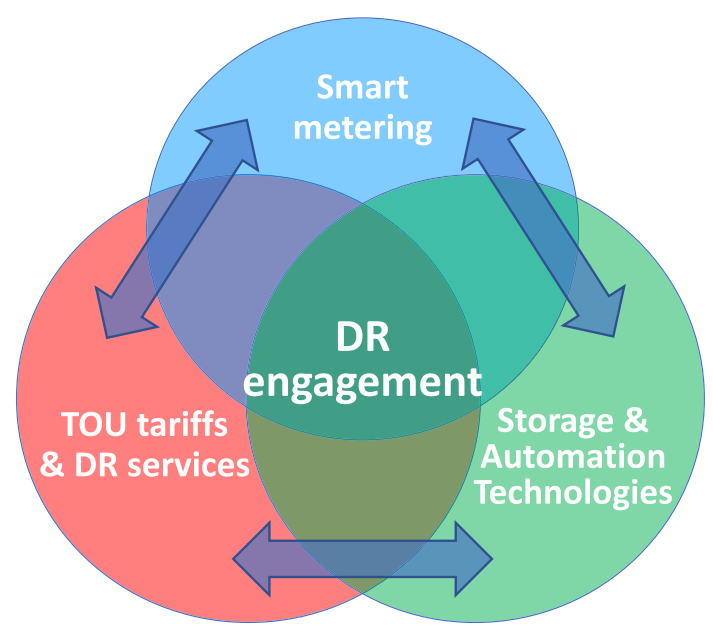

Fig. 1. The Demand Response Technology Cluster: promoting awareness that smart meters, smart tariffs, and storage and automation technologies enable greater benefits when combined could increase consumer engagement across all these technologies and services. Each component can act as an enabler and or driver for adoption of other components, e.g., smart meters enable smart tariff adoption and EVs and EV-tariffs could drive smart meter adoption.

\subsection{Promote smart tariffs, smart meters and electric vehicles as a 'technology cluster'}

Innovations are often understood by consumers not in isolation but as a cluster of inter-related innovative new ideas, products or services ${ }^{6}$; the adoption of one product may trigger the adoption of other related products [43]. However, the UK Government has set independent targets for smart meters, TOU tariffs and electric vehicles and these have largely been approached as discrete challenges for consumer engagement. TOU tariffs, smart meters, electric vehicles, heat pumps, storage, solar PV and other behind-the-meter smart-enabled energy technologies are not yet seen by consumers as inter-related elements for smart flexible consumption and decarbonisation.

Research for Citizens Advice found that only around 7\% of consumers identify the potential for accessing new products or services as a benefit of smart meters [96] (p.8). The Smart Meter Implementation Programme (SMIP) communication campaigns have so far focussed on households 'bringing consumption under control' [97] and on households reducing waste and consuming less rather than more flexibly [98, 99]. Recent SMIP TV campaigns have introduced the idea of smart meters supporting renewable energy $[100,101]$ but do not indicate how this is achieved or what a smart meter will enable households to do. Drawing on focus group research, Buchanan et al. [102] find that the current lack of a 'big picture' understanding of the smart grid by the public contributes to suspicion about smart meters. Buchanan et al. (Ibid) and Poyry \& Imperial College London [103] recommend that SMIP communications clarify the longer-term load-shifting objectives of smart metering as well as shorter-term accurate billing objectives.

Drawing on Diffusion-of-Innovation theory, we suggest here that supporting the perception of smart meters, smart tariffs, storage and automation technologies and other DR-enabling technologies as an inter-related technology cluster [43], delivering greater benefits for the individual, environment and society when combined, would be a more fruitful approach to consumer engagement with all of these DR-supporting technologies and services (see Fig. 1). A broadening of the SMIP campaign message could thereby drive not only greater

\footnotetext{
${ }^{6}$ For residential DR, innovation adoption encompasses services such as smart TOU tariffs, products such as smart meters and EVs, and ideas such as flexible consumption.
} 
household engagement with the smart meter rollout but greater interest and enthusiasm for EVs, smart tariffs and the whole cluster of associated technologies supporting flexibility, renewables, system efficiency and bill savings.

There are clear indications of the potential for engaging consumers via a multi-pronged approach not only through potential financial savings but also through consumers' approval of energy efficiency, local generation, renewable energy and sense of citizenship. Fell [39] found UK bill-payers' concern about climate change was positively associated with stated intention to take-up a dynamic TOU tariff presented as supporting renewable energy. In an online choice experiment, European and US respondents were more likely to report an interest in switching to a dynamic TOU tariff if they were shown environmental and system benefits [104]. The majority of Low Carbon London dynamic TOU trialists indicated either agreement or strong agreement that they would be more likely to sign up to a dynamic tariff if rate changes were linked to renewable generation (59\%) or to help society use energy more efficiently' (69\%) [40]. Similarly, the Customer-Led Network Revolution static TOU trial "provoked within people a sense of a civic relationship with the grid" [105] (p.26).

\subsection{Support adoption of EVs and other storage and automation technologies}

Wider ownership of storage and automation technologies could enable greater residential DR and would also incentivise suppliers, or DR aggregators, to introduce DR offerings to the market. Adoption of electric vehicles is further developed than that for other storage and automation technologies (e.g., smart heat pumps and thermal storage), in the UK and elsewhere, so the focus here will be on the potential for EVs to drive DR engagement in the nearer term. As outlined in Section 3.2.2, smart charging of EVs could deliver convenient, large, reliable and persistent DR. Therefore second recommendation we make here is that policy to support EV adoption should be pursued as a strategic route towards realising greater household engagement with DR in terms of both take-up and load-shifting.

UK sales of plug-in electric vehicles (PEVs) increased in 2019 to around $2.9 \%$ of new cars [106] but the Committee on Climate Change calculates that, in order to meet Net Zero goals, policy needs to aim for electric vehicles to reach $100 \%$ of new car and van sales by 2030 or 2035 at the latest [107]. This will require exponential growth in sales [108] and there is considerable uncertainty about whether this ambitious target will be met $[82,109]$.

The sale of new ICE and hybrid vehicles in the UK will be banned from 2035 and at present EV adoption is supported by a range of fiscal incentives [110]. EV-owners also enjoy a number of non-financial benefits which include less noise and superior performance [111]. Public support for cleaner energy is high [112] so EVs' compatibility with increasingly low-carbon electricity, and their reduced impact on local air quality, will also appeal to many consumers.

Barriers to EV adoption include supply bottlenecks and weak incentives for dealers to sell EVs [113], purchase costs and range anxiety. Policy recommendations put forward to lower other barriers to EV adoption include further support for EV charging networks, interoperability, and access to real-time information on chargepoint functionality [114].

\subsubsection{EV up-front costs}

Although the total cost of owning an electric car in the UK is already often lower than for an internal combustion or hybrid car [115], up-front cost is still considered the main barrier to wider EV adoption. Drawing on the evidence base for the effectiveness of purchase incentives for plug-in electric vehicles [116] suggests the most cost-effective measures to increase EV sales include strong grants to reduce up-front costs and increased awareness of financial incentives. The value of incentives offered in the UK is among the lowest of countries offering support for EV sales. This indicates the potential value of reinstating the UK grant for plug-in EVs to the previous level of $£ 4500$ (reduced to $£ 3500$ in 2018), offering VAT exemption for EV sales, such as in Norway and Iceland, and offering interest-free loans, as in Scotland [117]. Awareness of incentives is key to additionality (sales which would not have occurred without the policy measure) and consumer awareness of purchase incentives for EVs is generally low [116]. This suggests that Government incentives should be accompanied by more prominent awareness campaigns.

Even with the EV grant, a new electric car is still considered unaffordable for many households and the lower-cost second-hand market in electric vehicles is very small. In the UK, commercial fleet and company cars make up under $9 \%$ of registered cars but account for $57 \%$ of new car sales annually [118]. These cars move quickly into the private market (ibid.) and so support for fleet and company EV purchases could be an effective route for growing the second-hand EV market thereby making EVs more accessible in price. More company and fleet EVs will also increase the visibility of EVs which would help to normalise the technology leading to more rapid adoption [43]. In April 2020 changes to UK company car tax saw Benefit in Kind (BIK) tax for pure electric EVs reduced from $16 \%$ to zero (increasing to $1 \%$ in $2021-22$ and $2 \%$ in 2022-23). This could prompt a dramatic rise in take-up of electric vehicles for company cars [119].

\subsubsection{EV charging costs}

EV adoption could also be made more attractive by lowering running costs. A study by OVO Energy and Imperial College London concludes that introducing new regulation to maximise the market value of residential storage and flexibility could further reduce the cost of EV smartcharging and make all behind-the-meter devices that deliver flexibility more cost-effective for households:

"The biggest challenge to propagation of residential flexibility is the lack of route to market to grid balancing revenue streams from [behindthe-meter] devices. It is currently not possible to access the full system value identified by this study via existing flexibility markets, indicating a failing. Regulatory and market changes are required in order to facilitate the adoption of these technologies." [76] (p.16).

Increasing incentives for flexibility could be pursued by a 'flexibility first' approach in new regulation (Ibid) to support behind-the-meter devices through, for example, removing overpayment of final consumption levies and disproportionate network charges for storage [120]. Beyond the UK, European Parliament Directive 2019/944 on consumer empowerment and protection stipulates that, "Member States shall ensure that active customers that own an energy storage facility [...] are not subject to any double charges, including network charges, for stored electricity remaining within their premises or when providing flexibility services to system operators" [121] (Ch.III, Article 15).

New regulation to facilitate the stacking of consumers' and prosumers' revenue streams from an asset such as an EV or home battery [122], energy efficiency, energy conservation, solar self-consumption and DR could also make technology adoption and bundling more cost-effective and affordable. EU Directive 2019/944 [121] also requires that customers "are allowed to provide several services simultaneously, if technically feasible" (Ch.III, Article 15) and "Member States shall allow final customers, including those offering demand response through aggregation, to participate alongside producers in a non-discriminatory manner in all electricity markets" (ibid., Ch. III, Article 17).

Further support for storage could include extending the reduced $5 \%$ VAT level to all home battery installations - currently this reduced rate only applies to new battery and PV installation but not to adding batteries to existing PV [9] - or zero VAT-rating all home storage (electrical or thermal) and PV installations, as is the case in new build housing. In the UK exit from the EU is an opportunity to reduce VAT on home solar battery systems after it was increased in 2019 [123].

Burke, Byrnes, \& Fankhauser [124], Gissey et al. [125] and Hirst 
[126] all argue that carbon pricing (Carbon Price Support) successfully pushed coal off the grid and that a stronger carbon pricing mechanism could further decarbonise power and support flexibility linked to variable renewables.

\subsection{Enable informed adoption through improved competition, comparison and switching}

While greater awareness and affordability will support adoption of EVs and other smart storage, their uptake also depends on consumers gauging the financial benefits for their specific circumstances and household, comparing competing offerings and making the switch. At present these are all further barriers to DR engagement.

In a report for Which? on 'The Role of Demand-Side Remedies in Driving Effective Competition', Fletcher [65] considers three core categories of 'demand-side remedy': disclosure remedies (providing consumers with information about their products or services); shopping around remedies (facilitating search and comparison, such as via Price Comparison Websites) and switching remedies (for cheaper, quicker, more reliable and easier switching). Lowering adoption barriers using these remedies is discussed below.

\subsection{1 smart meters, next-day switching and half-hourly settlement}

Tariff switching currently takes an average of 15 days in the UK [127] and the slow switching process has been identified as a barrier to tariff engagement [128]. The UK regulator intends to introduce accurate next-day switching [129] and, beyond the UK, European Directive 2019/944 stipulates that, "By no later than 2026, the technical process of switching supplier shall take no longer than $24 \mathrm{~h}$ " (Article 12) [121].

Smart metering will permit these improvements to the switching process. Increasing the number of households with smart meters will also grow the potential market for DR services and technologies and the digital tools for comparing them, thereby supporting innovation and competition in offerings. The UK regulator, Ofgem, has also indicated that delivery of the smart meter rollout is setting the timeline for introducing a mandatory Market-wide Half-Hourly Settlement regime (MHHS) which would provide the right 'incentive framework' to encourage suppliers to bring forward innovative offerings and stimulate competition in helping consumers to manage and shift their consumption [68]. It will be important to maintain support for the rapid rollout of second generation (SMETS2) smart meters and for the swift enrolment of SMETS1 meters into the DCC to enable customers to switch between smart tariffs and bundled offerings from different suppliers. On the household engagement side, resolving interoperability issues, delivering next-day switching, and introducing mandatory market-wide HHS to stimulate DR offerings should add value to having a smart meter and help increase householder interest in getting one.

\subsubsection{Smarter digital comparison tools for shopping around}

Prospective EV buyers currently have no easy access to information about the lower EV running costs possible through a TOU tariff. Online running-cost calculators for EVs do exist (e.g., GoUltraLow.com, ne xtgreencar.com) but these calculations assume a flat-rate tariff and so do not factor in further savings from TOU tariffs or other DR services. Similarly, for consumers considering purchasing solar PV, the available calculators showing cost, revenue and pay-back periods do not incorporate smart tariffs or battery storage options.

Nor are smart TOU tariffs included in the market comparisons of residential energy contracts provided on price comparison websites (PCWs) either in the UK or, to the authors' knowledge, elsewhere. In Sweden consumers have been able to choose dynamic pricing contracts (which follow the Nord Pool spot market) since 2012 but less than $1 \%$ do so [60]. The Swedish regulator hopes that the number of customers will rise once these contracts become introduced in their comparison tool (more realistic estimates of cost savings based on the consumer's consumption profile and their potential for load-shifting may be possible when the Swedish data hub is in place in 2021). In Norway, spot-price contracts are very common (70\% of households). Few households have a smart meter, however, and consumers are billed on the basis of average consumption profiles. In Spain the residential consumer default tariff is based on dynamic pricing but there is no way at present for households to calculate ex-ante (in advance) their savings from dynamic pricing and DR (ibid.).

At an EU level, EC Directive 2019/944 states: "Member States shall ensure that at least household customers [...] have access, free of charge, to at least one tool comparing the offers of suppliers, including offers for dynamic price contracts [...] Member States shall ensure that at least one tool covers the entire market" (Ch.III Article 14; emphasis added) [121]. However, a 'shopping around' remedy for DR services and EV-adoption appears far from being delivered. The absence of TOU tariffs from market comparisons on PCWs or other digital comparison tools (DCTs), and the challenges facing their inclusion, are not widely acknowledged. The academic and grey literature that considers adoption of demand response and TOU tariffs has tended to neglect PCWs despite their importance to switching habits, at least in the UK. Likewise, DR and TOU have been overlooked in reports considering competitive energy markets [47] and digital comparison tools [50,55,130-132]. This absence of smart tariffs on DCTs is likely to become a bottle-neck for consumer engagement with smart TOU tariffs and EVs and therefore residential DR.

DCTs that allow customers to compare TOU tariffs and other DR services, in combination with DR-supporting technologies such as EVs, could enable informed customer choices and reduce barriers to adoption. Suppliers offering smart tariffs (perhaps bundled with hardware) can provide potential consumers with estimates of energy costs based on similar households. But these are approximate and do not offer a comparison with other products and services available on the market, which may vary in terms of exposure to electricity price volatility, nonfinancial considerations and consumer satisfaction. A rare and sustained consideration of PCWs for the adoption of DR services is found in He, Azevedo and Meeus [133], who argue that price comparison tools (or 'contract comparison tools') are necessary for DR because of the variety in consumer load mix, flexibility, consumer preferences and the consequent difficulty in selecting tariff type and specific contract duration and terms.

There are, however, some technical and regulatory obstacles to including TOU and DR services on digital comparison tools which may need to be addressed and these are discussed below.

\subsubsection{Barriers to digital comparison tools for $D R$ and EV adoption}

4.3.3.1. Regulation of digital comparison tools and more open data. In the UK context, Ofgem's Confidence Code for DCTs is underpinned by four main principles: "independence, transparency, accuracy and reliability" [134] (p.6). Some more prescriptive elements to the code may present obstacles to the inclusion of TOU. For instance, there is a default comparison period of 12 months (ibid., p.31) which may not be appropriate if hardware (such as an EV or home battery) is bundled with tariffs under longer contracts.

Further, current regulations make it mandatory for PCWs to rank contracts by cost [135]. Citizens Advice [130] question the primacy given to price information and recommend that PCWs include non-price information covering company and customer service performance indicators as these can be important for customer satisfaction. Indicators about the green credentials of the DR service will also be of interest to some consumers and some small suppliers have called for tariff labelling to provide consumers with information about the source of generation and other ethical criteria [136]. This greater transparency could facilitate product differentiation and perhaps help to clarify the system and environmental benefits of DR products.

Producing cost-projections of a household's bill for a dynamic tariff 


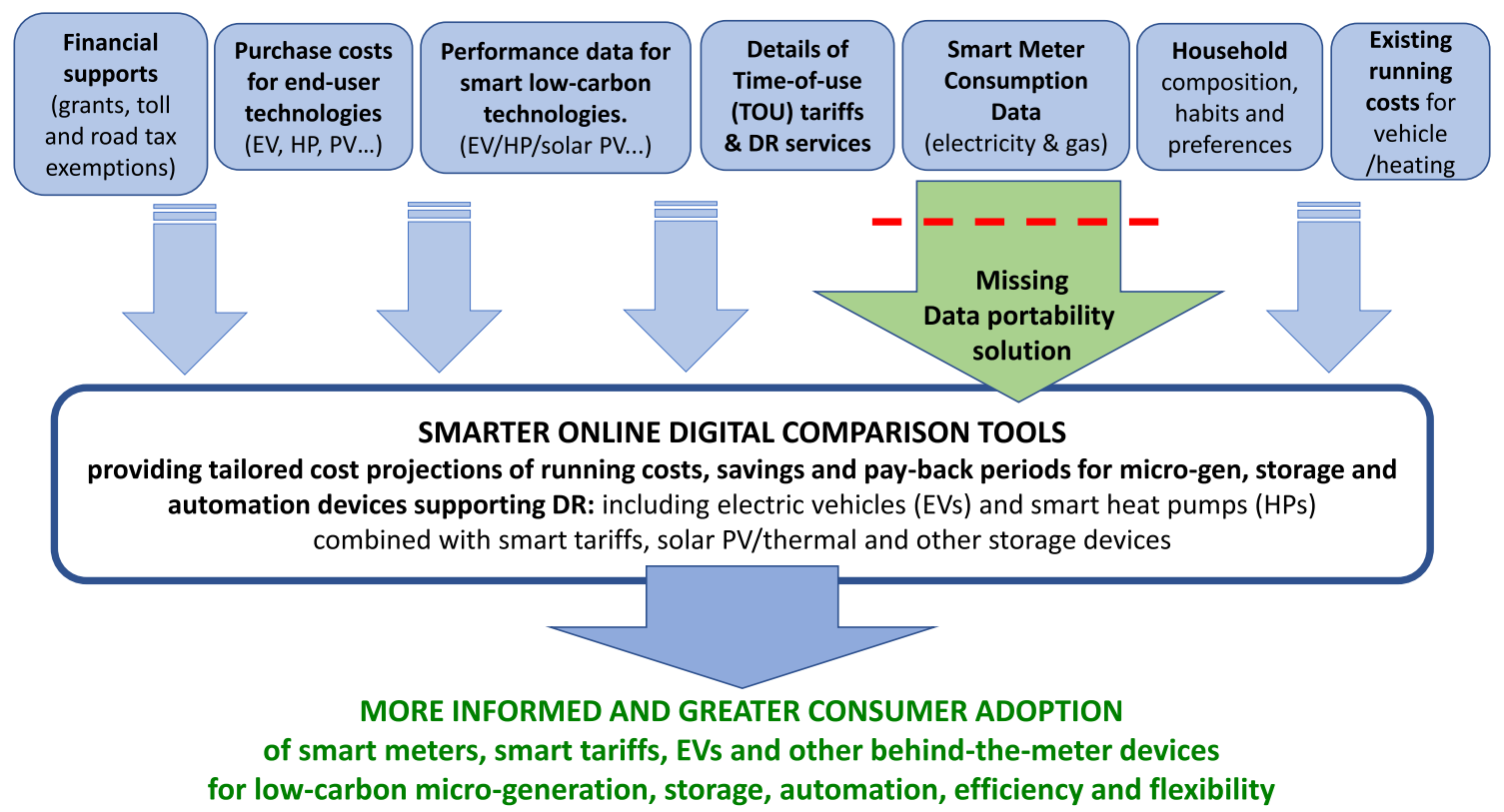

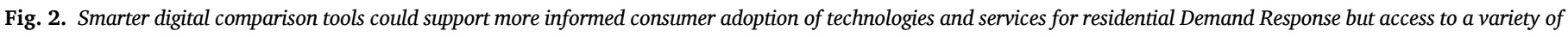
data and a solution to allow households to share their smart meter data with third parties are needed (Source: adapted from Carmichael 2019 [140]).

would be challenging if based on future loadshifting through behavioural or manual response (at least for households who have not been on a smart TOU tariff before). In contrast, automation and storage technologies can not only deliver greater volume of demand response but can do so more reliably, thereby making accurate projections of household consumption and bills more feasible. More open data - as advocated by the Energy Data Taskforce [137] and others [138,139] would facilitate the inclusion of behind-the-meter technologies in consumer bill projections. Performance data for smart and low-carbon technologies is one of a range of data inputs that could help deliver smarter DCTs - see Fig. 2.

Ofgem's Confidence Code for DCTs also requires that each DCT's results be 'accurate' and that it "takes responsibility for obtaining, updating and ensuring the accuracy of all data" (p.30) [135]. The complexity of modelling energy costs for 48 half-hour settlement periods per day is not trivial. The need for accuracy, and ideally standardisation across PCWs, combined with the initially small number of smart tariffs and customers switching to them, suggests that duplication of effort and inertia might be avoided by using a white label solution whereby one party builds the DCT for TOU tariffs with this same tool being used by all PCWs. One PCW interviewed for this paper viewed the technical challenge as being manageable compared to other barriers, notably: the limited number of households with a DCC-enrolled smart meter allowing them to switch to smart TOU offerings; and barriers to consumers sharing their smart meter data with PCWs.

4.3.3.2. Data portability solutions. A range of data would be required to offer the digital comparison tool services outlined above. This could include: some household data entered manually (such as appliance ownership, household composition, preferences and vehicle usage patterns); market data (including smart tariff details, vehicle purchase costs, grants and tax exemptions); and technical data on the performance of technologies (such as EV or home batteries, PV, charging technology, smart controls etc). As electricity costs under a TOU tariff are affected by the electricity consumption patterns of the whole household, ${ }^{7}$ the required data should also include the household's halfhourly consumption data from their smart meter. Most consumers are relatively unconcerned about sharing smart meter data [63,141]. Research by Ofgem finding that bill-payers rank half-hourly energy consumption data as much less sensitive than most other kinds of personal data [142]. About half would share smart meter data with chosen third parties to receive personal benefits and two-thirds to improve the operational efficiency of the system or market; willingness to share this data was higher among consumers with a smart meter (Ibid). Data might also be shared anonymously by DCT users to get tailored advice about tariff and technology options - providing such a mechanism existed. However, an important barrier to the emergence of DCTs for consumer engagement and adoption of DR products and services is the current lack of infrastructure enabling consumers to share, or 'port', their half-hourly electricity consumption smart meter data to third parties [138], as shown in Fig. 2.

Activities in the area of consumer energy data portability in the UK are ongoing within Midata [143], which aims to provide consumers with a service for "electronically transferring customers' data (with their consent), from a supplier's system to a Third Party Intermediary (TPI)" (p.5) [128]. As yet, Midata is unable to handle the half-hourly data that would be needed for price comparison websites to advise accurately on TOU offerings [130]. A call for evidence on implementing Midata in the energy sector concluded that the new data fields include, "consumption data by time of use for those customers on Economy 7 (or other time-of use tariff) as recommended by the CMA [Competition and Markets Authority] to enable a more tailored tariff comparison for customers with non-standard tariffs" (p.17) [128]. However, enabling all households to share their half-hourly usage data would better support adoption decisions across all households including those switching to a TOU tariff for the first time.

At present, the most direct solution for data portability in the UK is for third parties to become registered users of the Data Communications Company (DCC) secure network for accessing smart meter data. However, considerable complexity and cost is involved [144], which

\footnotetext{
7 This could change if meter splitting allows a consumer to have multiple energy providers - for example, one supplier for EV charging and one for household appliances. See https://www.elexon.co.uk/mod-proposal/p379/.
} 
suggests the need for an intermediary to facilitate this. The Smart Meter Data Public Interest Advisory Group (PIAG) work notes that there is also potential for an alternative route via Consumer Access Devices (CADs) that collect highly granular (10-s) data via the Home Area Network (HAN) which could then be shared with selected third parties via the customer's broadband (Ibid) (13 months of data is stored on the smart meter). CADs may prove to be a good route to smart energy management and flexibility services but, at least in the short-term, households do not have these in order to enable data portability.

\section{Conclusions and research and policy implications}

\subsection{Key findings}

In this paper we have argued that the evidence base for residential consumer engagement with DR has delivered some insights into manual load-shifting but the deficiencies of that evidence base increasingly risks holding back thinking about the future of residential DR. Data sets that are dominated by manual flexibility and stated preference methods that reproduce barriers to informed adoption decisions need to be balanced by greater attention to evidence on unlocking opportunities for increasing DR. We have advocated a shift from efforts to measure and predict DR engagement to a more action-oriented focus on addressing barriers to engagement, innovation and competition, thereby helping to close the existing gap between stated willingness to adopt TOU tariffs and actual adoption rates. The paper has proposed three main strategies which could improve consumer engagement with DR in the UK context. These strategies could also apply to other regions moving towards smarter, more flexible low-carbon electricity for households and adoption of smart metering and EVs.

Firstly, instead of approaching them as separate consumer engagement challenges, we suggest promoting greater understanding of DR services, smart meters, storage and automation technologies, and renewable energy as mutually-supportive elements within a common 'technology cluster' that delivers household savings, system efficiency and decarbonisation. This could be pursued, for example, by broadening the smart meter awareness campaign but would be more impactful if backed-up with new policy to make combining elements of this technology cluster more cost-effective.

Secondly, engagement with DR could be strengthened through greater support for the adoption of EVs and other storage and automation technologies with large flexible loads that can reliably deliver substantial volumes of DR. This could include increasing financial support for up-front technology costs and improving public awareness of these supports. New regulation allowing suppliers, aggregators and consumers greater access to the market value of residential flexibility could also play an important role in incentivising innovative DR offerings and consumer investment in DR-enabling technologies such as EVs.

Finally, the complexity of the consumer decisions around DR services and technologies underlines the urgent need to address barriers to informed 'shopping around' and switching. We strongly recommend the rapid implementation of next-day switching and support for the development of digital comparison tools (DCTs) to include smart tariffs and bundled offerings that enable DR (e.g., EVsleased with EV-tariff) ${ }^{8}$. Measures to facilitate these new market comparisons on DCTs should include resolving smart meter data portability issues. Well-developed and regulated DCTs could also be important for protecting customers

\footnotetext{
${ }^{8}$ Since this manuscript was submitted, BEIS have funded the Smarter TariffsSmarter Comparisons project which is now developing and testing an open source tool to include smart tariffs in comparisons. The project runs June 2020 to March 2021 and the multi-partner consortium, led by Vital Energi, includes the corresponding author of this article. See https://www.gov.uk/governme nt/publications/smart-meter-enabled-tariffs-comparison-project-smarter-tar iffs-smarter-comparisons.
}

and mitigating the risk of households experiencing negative outcomes especially important while these services are still unfamiliar to consumers.

Two further general observations may also be made about these recommendations and are not specific to the UK.

\subsection{Modelling for consumers not of consumers}

The complex work required for DCTs to provide households with tailored cost projections (using data on consumption patterns and flexibility, tariff design and various behind-the-meter devices) would also represent a departure from the usual focus in energy modelling. Energy modelling fulfils a variety of purposes: simulation, engineering or investment optimisation [145], or (as in the annual Future Energy Scenarios by National Grid, UK) those that "model possible consumer behaviours" (p.8) [146]. The usual focus is on the system-level impact of aggregated consumption, behaviour, costs, and technical performance. In contrast to trying to predict consumer behaviour and/or simulate its aggregated impact, there is also an opportunity for modelling to play a much greater role as an intervention to support consumer engagement. DCTs could do this by supporting consumers' adoption decisions based on cost projections (or cost optimisation) at the level of a single household. Not modelling of consumers but modelling for consumers. For the uncharted and uncertain territory of consumer engagement with innovative DR-services and technologies, this more action-oriented and engaged role for modelling is consistent with Fazey et al.'s advocacy for science as intervention and their observation that "For wider transformations to low carbon living and energy systems to occur, transformations will therefore also be needed in the way in which knowledge is produced and used" (p.55) [8]. This shift from prediction to more enabling and action-oriented modelling would put into practice the variously-attributed saying, 'the best way to predict the future is to create it'.

\subsection{Interdependency and urgency}

This paper has argued for the need for a more joined-up approach to engagement with DR that recognises the interdependencies between numerous elements within a cluster of technologies for smart, flexible low-carbon energy: renewable energy (both grid-level and microgeneration), residential demand response, smart time-varying electricity tariffs and other DR services, storage and automation technologies (such as EVs and smart charging) and smart metering infrastructure. The role of additional technologies and infrastructure for enabling and accelerating consumer engagement with this cluster has also been highlighted: improved switching, data portability, open data, digital comparison tools, and incentive frameworks for DR offerings.

This interdependence and complexity promises greater efficiency, savings and impact for decarbonisation but also presents a 'chicken or egg' sequencing problem for policy and consumer engagement strategy and a risk of deadlock. Such interdependencies mean that delivery of one element may be purposefully deferred until another is sufficiently progressed - for example, the UK regulator's introduction of a mandatory market-wide half-hourly settlement (MHHS) regime is being held back by the delayed smart meter rollout. Another example is the deliberately slow evolution of the smart meter awareness campaign to avoid introducing the public too quickly to the 'big picture' for smart metering. While in some cases this may be unavoidable (as in the case of MHHS), there is a danger that these interdependencies will lead to lengthy delays. The urgent need for deep decarbonisation - including an ambitious shift to renewables and flexibility - means that it will be necessary to push the pace of as many of these components as possible rather than allowing progress being determined by the slowest component. This could be pursued by a sustained commitment to rolling out the required infrastructure: smart meters, next-day switching, dataportability, 'smarter' digital comparison tools, EV-charging networks, 


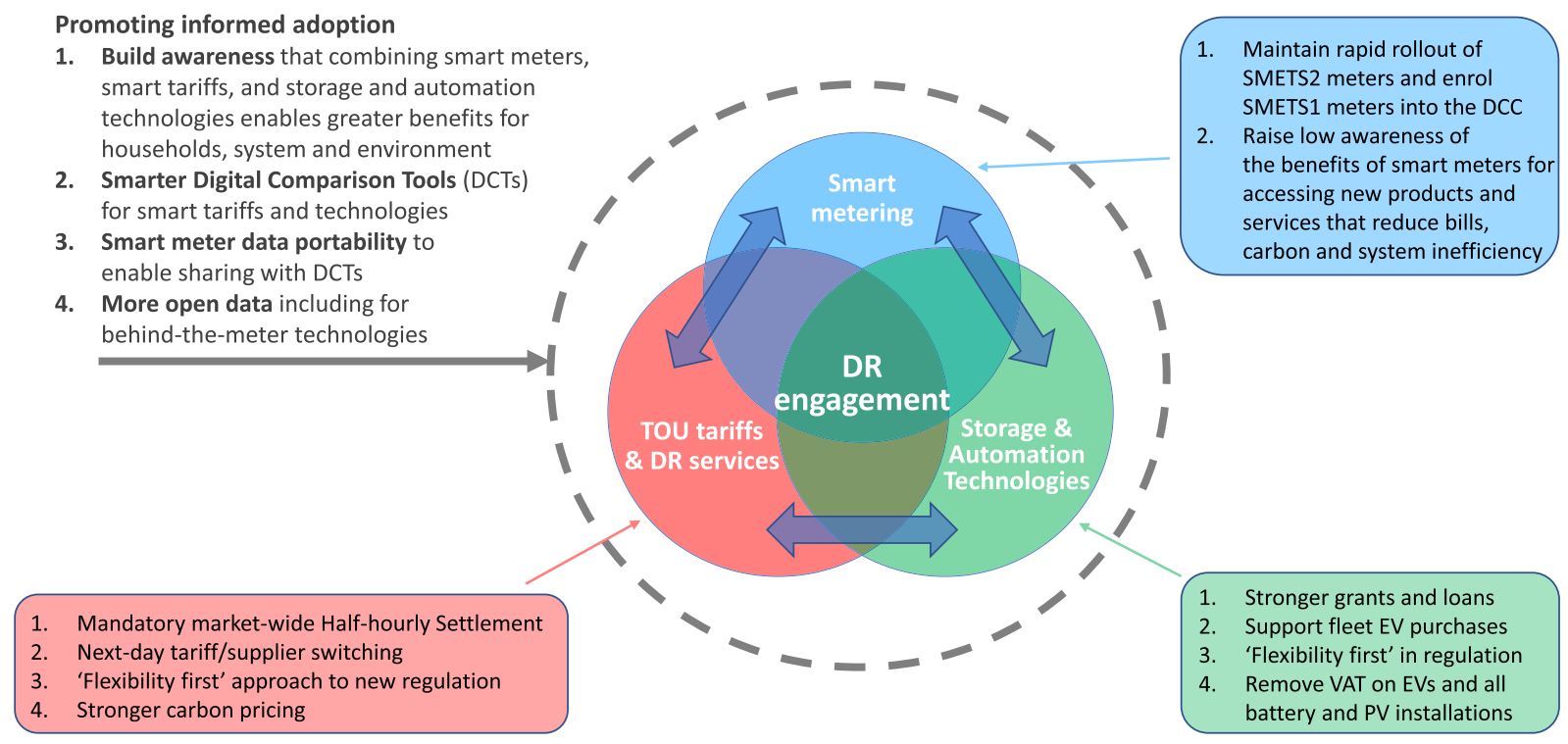

Fig. 3. The Demand Response Technology Cluster with recommendations for supporting all components, individually and collectively.

policy frameworks to incentivise market offerings for DR, and new regulation for third party consumer services and consumer protections. Recommendations for policy and other interventions to support components of the Demand Response Technology Cluster, individually and collectively, are summarised in Fig. 3.

\section{Credit author statement}

Richard Carmichael: Conceptualization, Investigation, Writing original draft, Visualization, Writing-reviewing and editing. Robert Gross: Funding acquisition, Supervision, Writing-reviewing and editing. Richard Hanna: Writing-reviewing and editing. Aidan Rhodes: Writingreviewing and editing. Tim Green: Funding acquisition, Writing- reviewing and editing.

\section{Declaration of competing interest}

The authors declare that they have no known competing financial interests or personal relationships that could have appeared to influence the work reported in this paper.

\section{Acknowledgements}

This work was supported by ESRC funding (grant reference number, ES/M500562/1) through the Imperial College London Impact Acceleration Account (IAA) via Energy Futures Lab.

\section{Appendix A. Search protocols}

Search terms used

\begin{tabular}{|c|c|c|c|}
\hline Demand Response & $\begin{array}{l}\text { Evidence/ } \\
\text { document }\end{array}$ & Intervention & $\begin{array}{l}\text { Technology/ } \\
\text { Additional terms }\end{array}$ \\
\hline $\begin{array}{l}\text { demand response } \\
\text { demand * response } \\
\text { demand side response } \\
\text { flexibility } \\
\text { load-shifting } \\
\text { peak-shaving } \\
\text { behaviour change/behaviour change } \\
\text { active demand } \\
\text { OR } \\
\text { Smart tariff direct control real-time pricing } \\
\text { critical peak pricing } \\
\text { critical peak rebate } \\
\text { time-of-use } \\
\text { time-varying/dynamic } \\
\text { cost-reflective } \\
\text { pricing/tariff/price signals } \\
\text { TOU smart home rate }\end{array}$ & $\begin{array}{l}\text { Trial } \\
\text { pilot } \\
\text { program } \\
\text { programme } \\
\text { initiative } \\
\text { service } \\
\text { intervention } \\
\text { technology } \\
\text { services }\end{array}$ & $\begin{array}{l}\text { Consumer customer } \\
\text { trialist } \\
\text { household } \\
\text { residential } \\
\text { OR Engagement attitudes } \\
\text { experience } \\
\text { responsiveness } \\
\text { respons* } \\
\text { take-up } \\
\text { OR } \\
\text { uptake } \\
\text { participation } \\
\text { adopt* } \\
\text { results/findings } \\
\text { report } \\
\text { OR } \\
\text { model } \\
\text { Modelling/modelling energy system(s) modelling/modelling }\end{array}$ & $\begin{array}{l}\text { Electric vehicles/EV } \\
\text { Photovoltaic/PV } \\
\text { technologies } \\
\text { smart appliances } \\
\text { OR } \\
\text { electricity energy } \\
\text { Storage } \\
\text { Battery/ies }\end{array}$ \\
\hline
\end{tabular}

\section{Example search string}

Main search string used for Google: "demand * response" OR flexibility OR "load-shifting" OR "Smart" OR "real-time" OR "time-of-use" OR "timevarying" OR "dynamic" OR "cost-reflective" "price" OR pricing OR signals OR tariff engagement OR participation OR adoption OR "take-up" OR 
attitudes OR accept OR responsiveness filetype:ps OR filetype:pdf OR filetype:doc OR filetype:docx

\begin{tabular}{ll}
\hline Inclusion criteria & Exclusion criteria \\
\hline •UK and non-UK locations & $\bullet$ Non-English language publications \\
$\bullet$ Field pilots/trials & $\bullet$ Publication date before 2005 \\
•Qualitative and quantitative research with consumers & \\
•Meta-reviews & \\
•Academic and 'grey' literature & \\
\hline
\end{tabular}

\section{Protocol for literature search}

1. Run search strings in databases (Science Direct/Google) and record search results (database, search string, number of hits) into Excel table.

2. Manually filter for relevance (usually top 100 results) based on title, or title and abstract.

3. Download filtered documents.

4. Record in Excel file a Relevance Rating (1-4) for each document based on abstract, and or quick scan of document and other notes on document.

5. Literature with highest relevance ratings imported into Mendeley reference management software and sorted into sub-folders for various features (e.g., UK, USA), type of TOU (e.g., fixed, dynamic), type of technology (e.g., PV, battery, automation).

6. Detailed reading.

\section{References}

[1] Energy \& Climate Intelligence Unit. Net zero tracker: 2020 scorecard 2020:1-4. https://eciu.net/netzerotracker.

[2] Committee on Climate Change (CCC). Net Zero: the UK's contribution to stopping global warming. 2019.

[3] Hertwich EG, Peters GP. Carbon footprint of nations: a global, trade-linked analysis. Environ Sci Technol 2009;43:6414-20.

[4] Wilson J, Tyedmers P, Spinney JEL. An exploration of the relationship between socioeconomic and well-being variables and household greenhouse gas emissions. J Ind Ecol 2013;17:880-91.

[5] Dubois G, Sovacool B, Aall C, Nilsson M, Barbier C, Herrmann A, et al. It starts at home? Climate policies targeting household consumption and behavioral decisions are key to low-carbon futures. Energy Res Soc Sci 2019;52:144-58. https://doi.org/10.1016/j.erss.2019.02.001.

[6] Carreiro AM, Jorge HM, Antunes CH. Energy management systems aggregators: a literature survey. Renew Sustain Energy Rev 2017;73:1160-72. https://doi.org/ 10.1016/j.rser.2017.01.179.

[7] Paterakis NG, Erdinç O, Catalão JPS. An overview of Demand Response: keyelements and international experience. Renew Sustain Energy Rev 2017;69: 871-91. https://doi.org/10.1016/j.rser.2016.11.167.

[8] Fazey I, Schäpke N, Caniglia G, Patterson J, Hultman J, van Mierlo B, et al. Ten essentials for action-oriented and second order energy transitions, transformations and climate change research. Energy Res Soc Sci 2018;40:54-70. https://doi.org/10.1016/j.erss.2017.11.026.

[9] BEIS. The Clean Growth Strategy: leading the way to a low carbon future. 2017.

[10] National Grid. Future energy scenarios. National Grid; 2019.

[11] BloombergNEF. New energy outlook. BloombergNEF; 2018.

[12] Strbac G, Pudjianto D, Sansom R, Djapic P, Ameli H, Shah N, et al. Analysis of Alternative UK Heat Decarbonisation Pathways, a report for the Committee on Climate Change. Imperial College London; 2018.

[13] Committee on Climate Change. Hydrogen in a low-carbon economy. 2018.

[14] Strbac G, Aunedi M, Pudjianto D, Teng F, Djapic P, Druce R, et al. Value of flexibility in a decarbonised grid and system externalities of low-carbon generation technologies. Imp Coll London, NERA Econ Consult 2015. https://doi org/10.13140/RG.2.1.2336.0724.

[15] Carbon Trust \& Imperial College London. An analysis of electricity system flexibility for Great Britain. Carbon Trust; 2016.

[16] Heptonstall P, Gross R, Steiner F. The costs and impacts of intermittency - 2016 update electricity generation technologies. UKERC; 2017.

[17] Strbac G, Aunedi M, Pudjianto D, Djapic P, Gammons S, Druce R. Understanding the balancing challenge (a report for DECC). Imperial College London/NERA; 2012.

[18] BEIS. Electricity statistics 2018 Q2: section 5 - electricity. 2018.

[19] OFGEM. Upgrading our energy system: smart systems and flexibility plan. OFGEM; 2017.

[20] BEIS. Smart Meter roll-out cost-benefit analysis. BEIS; 2016. Part I.

[21] Parrish B, Gross R, Heptonstall P. On demand: can demand response live up to expectations in managing electricity systems? Energy Res Soc Sci 2019;51: 107-18. https://doi.org/10.1016/j.erss.2018.11.018.

[22] Chase A, Gross R, Heptonstall P, Jansen M, Kenefick M, Parrish B, et al. Realising the potential of demand-side response to 2025 - Summary report. BEIS; 2017.

[23] Hledik R, Gorman W, Irwin N, Fell M, Nicolson M, Huebner G. The Value of TOU Tariffs in Great Britain: Insights for Decision-makers Volume I: Final Report, A report for Citizens Advice. Brattle Group/UCL; 2017.

[24] Cambridge Economic Policy Associates Ltd (CEPA). Distributional impact of time of use tariffs - final report for Ofgem. OFGEM; 2017.
[25] Srivastava A, Van Passel S, Laes E. Assessing the success of electricity demand response programs: a meta-analysis. Energy Res Soc Sci 2018;40:110-7. https:// doi.org/10.1016/j.erss.2017.12.005.

[26] Nicolson ML, Fell MJ, Huebner GM. Consumer demand for time of use electricity tariffs: a systematized review of the empirical evidence. Renew Sustain Energy Rev 2018;97:276-89. https://doi.org/10.1016/j.rser.2018.08.040.

[27] Stromback J, Dromacque C, Yassin MH. Empower Demand - The potential of smart meter enabled programs to increase energy and systems efficiency: a mass pilot comparison. VaasaETT; 2011.

[28] Kaplan A. The conduct of inquiry: methodology for behavioural science. San Francisco, CA: Chandler; 1964.

[29] Hendrix CS. The streetlight effect in climate change research on Africa. Global Environ Change 2017;43:137-47. https://doi.org/10.1016/j. gloenvcha.2017.01.009.

[30] Freedman DH. Wrong: why experts keep failing us - and how to know know when not to trust them. New York: Little, Brown and Co.; 2010.

[31] Collins A, Miller J, Coughlin D, Kirk S. The production of quick scoping reviews and rapid evidence assessments: a how to guide. Defra/NERC; 2015.

[32] Sorrell S. Improving the evidence base for energy policy: the role of systematic reviews. Energy Pol 2007;35:1858-71. https://doi.org/10.1016/j. enpol.2006.06.008.

[33] Shipworth D, Fell MJ, Elam S. Response to "Vulnerability and resistance in the United Kingdom's smart meter transition”. Energy Pol 2019;124:418-20. https:// doi.org/10.1016/j.enpol.2018.08.039.

[34] Greenhalgh T, Peacock R. Effectiveness and efficiency of search methods in systematic reviews of complex evidence: audit of primary sources. Br Med J 2005; 331:1064-5. https://doi.org/10.1136/bmj.38636.593461.68.

[35] Carmichael R, Gross R, Rhodes A. Unlocking the potential of residential electricity consumer engagement with demand response: an Energy Futures Lab briefing paper. Imperial College London; 2018.

[36] EPRI. Understanding electric utility customers - Summary Report: What We Know and What We Need to Know. Palo Alto, CA: EPRI; 2012.

[37] Sustainability First \& Centre for Sustainable Energy. Response to Ofgem: Consultation on access to half-hourly electricity data for settlement purposes. Sustainability First \& Centre for Sustainable Energy; 2018.

[38] Fell MJ, Nicolson M, Huebner GM, Shipworth D. Is it time?. Consumers and time of use tariffs: trialling the effect of tariff design and marketing on consumer demand for demand-side response tariffs. UCL/Smart Energy GB; 2015.

[39] Fell MJ. Taking charge: perceived control and acceptability of domestic demandside response (doctoral thesis). UCL; 2016.

[40] Carmichael R, Schofield J, Woolf M, Bilton M, Ozaki R, Strbac G. Residential consumer attitudes to time-varying pricing, Report A2 for the "Low Carbon London" LCNF project. Imperial College London; 2014.

[41] Citizens Advice. False economy: missed opportunities and failures in the "time of use' tariff market. Citizens Advice; 2018.

[42] Dütschke E, Paetz A-G. Dynamic electricity pricing-which programs do consumers prefer? Energy Pol 2013;59:226-34. https://doi.org/10.1016/J. ENPOL.2013.03.025.

[43] Rogers EM. Diffusion of innovations. fifth ed. New York: Free Press; 2003.

[44] Smart Energy GB/Incite. Smarter Living: what consumers want from new smart energy products and services. Smart Energy GB; 2017.

[45] OFGEM. Decision: Selection criteria for mandatory supplier testing of measures to promote domestic consumer engagement (Letter to all domestic electricity and gas suppliers, consumer groups and other stakeholders). OFGEM; 2017.

[46] Helm D. Cost of energy review. 2017.

[47] CMA. Modernising the energy market. 2016.

[48] GfK UK Social Research. Consumer engagement in the energy market 2017: report on a survey of energy consumers. 2017. 
[49] Smart Energy GB. The smart future: lifestyle tariffs. Smart Energy GB; 2019.

[50] Which?. Response to the CMA's Statement of Scope for its market study on Digital Comparison Tools (DCTs). Which?; 2017.

[51] Jackson G. Octopus Response to CMA DCTs market report. 2017.

[52] He X, Reiner D. Consumer engagement in energy markets: the role of information and knowledge (working paper). 2018. https://doi.org/10.17863/CAM.33801.

[53] CMA. Digital comparison tools market study - Update Paper. CMA; 2017.

[54] OFGEM. Helping consumers make informed choices - proposed changes to rules around tariff comparability and marketing. OFGEM; 2016.

[55] CMA. Digital comparison tools market study - Final report. CMA; 2017.

[56] OFGEM. (Letter) Modification of electricity and gas supply licences to introduce five 'informed choices' principles and remove the majority of the prescriptive sales and marketing rules. OFGEM; 2017.

[57] Citizens Advice. Trust in the energy sector and billing. Citizens Advice; 2016.

[58] Chernev A, Böckenholt U, Goodman J. Choice overload: a conceptual review and meta-analysis. J Consum Psychol 2015;25:333-58. https://doi.org/10.1016/j. jcps.2014.08.002.

[59] Strong C. Consumers' hierarchies of priorities, A research report for Citizens advice. 2014.

[60] CEER. Implementing Technology that benefits consumers in the clean energy for all Europeans package: selected case studies. CEER report ref C19-IRM-16-04 2019.

[61] Wilson T, Aronson E, Carlsmith K. The art of laboratory experimentation. In: Fiske Susan T, Daniel T, Gilbert GL, editors. Handb. Soc. Psychol. fifth ed.1. John Wiley \& Sons; 2010. p. 49-79.

[62] He X, Reiner D. Why consumers switch energy suppliers: the role of individual attitudes. Energy J 2017;38:25-53.

[63] Navigator. Smart Metering data access and privacy: public attitudes research. DECC; 2012.

[64] Waddams Price C, Zhu M. Empirical evidence of consumer response in regulated markets. J Compet Law Econ 2016;12:113-49. https://doi.org/10.1093/joclec/ nhv041.

[65] Fletcher A. The role of demand-side remedies in driving effective competition: a review for Which? Centre for Competition Policy, University of East Anglia; 2016.

[66] UK Department for Business Energy \& Industrial Strategy (BEIS). Smart meter statistics in great Britain: quarterly report to end september. BEIS; 2019. https://a ssets.publishing.service.gov.uk/government/uploads/system/uploads/attachm ent_data/file/848325/2019_Q3_Smart_Meters_Statistics_Report.pdf.

[67] DCC. Way clear for second cohort of 1st-generation smart meters to be enrolled on central network 2019:1-2, https://www.smartdcc.co.uk/news-and-insights /news/update-on-smets1-enrolment-and-adoption/. [Accessed 31 July 2019].

[68] Ofgem. Market-wide half-hourly settlement: strategic outline case 2018.

[69] Hledik R, Faruqui A, Weiss J, Brown T, Irwin N. The Tariff Transition Considerations for Domestic Distribution Tariff Redesign in Great Britain, Volume I. Final Report; Brattle Group/Citizens Advice; 2016.

[70] ICF Consulting. Overview of the Electric Vehicle market and the potential of charge points for demand response. DECC; 2016.

[71] Hall S. The smart route to electric vehicles. Smart Energy GB; 2018.

[72] Rhys J. Cost Reflective Pricing in Energy Networks: the nature of future tariffs, and implications for households and their technology choices. Energy Systems Catapult; 2018.

[73] Octopus Energy. Agile Octopus: a consumer-led shift to a low carbon future. 2018.

[74] goultralow.com. The Benefits of owning an electric car 2019:1-6. https://www. goultralow.com/ev-owners/benefits/.

[75] BEIS. Table 2.6.2. Average expenditure each week on fuel per consuming household. ONS; 2019. https://www.ons.gov.uk/peoplepopulationandcommuni ty/personalandhouseholdfinances/expenditure/adhocs/009534averageweeklyho useholdexpenditureonfuelbygrossincomedecilegroupukfinancialyearending2018.

[76] OVO Energy \& Imperial College London. Blueprint for a post-carbon society: how residential flexibility is key to decarbonising power, heat and transport. OVO Energy \& Imperial College London; 2018.

[77] EA Technology. Smart charging: a brief guide to managed electric vehicle home charging. Western Power Distribution; 2017.

[78] EA Technology. Consultation on managed electric vehicle charging: summary of responses. 2017.

[79] Fell MJ, Shipworth D, Huebner GM, Elwell CA. Public acceptability of domestic demand-side response in Great Britain: the role of automation and direct load control. Energy Res Soc Sci 2015;9:72-84. https://doi.org/10.1016/j. erss.2015.08.023.

[80] Smart Energy GB.. The smart route to electric vehicles: smart meters will put Britain's electric vehicle revolution in the fast lane, vols. 1-7. Smart Energy GB 2018. https://www.smartenergygb.org/en/resources/press-centre/press-re leases-folder/smart-route-to-electric-vehicles.

[81] Green Alliance. How the UK can lead the electric vehicle revolution. London: Green Alliance; 2018.

[82] Mazur C, Offer GJ, Contestabile M, Brandon NB. Comparing the effects of vehicle automation, policy-making and changed user preferences on the uptake of electric cars and emissions from transport. Sustainability 2018;10:4-6. https:// doi.org/10.3390/su10030676.

[83] Chediak M. The latest bull case for electric cars: the cheapest batteries ever. BloombergCom 2017;vol. 8. 2017, https://www.bloomberg.com/news/article s/2017-12-05/latest-bull-case-for-electric-cars-the-cheapest-batteries-ever.

[84] Solar Trade Association. Smart export guarantee. 2019. https://www.solar-trade. org.uk/seg/.
[85] Institute for Energy Economics and Financial Analysis (IEEFA). Electric vehicles and batteries can drive growth of residential solar: EV and battery cost reductions important for encouraging new demand. 2019.

[86] Renault.co.uk. Renault Finance - Battery hire: 2019: https://www.renault.co.uk/ renault-finance/battery-hire.html..

[87] Powervault.co.uk. Powervault partners with Octopus Energy to enhance the benefits of smart tariffs and smart batteries. Powervault; 2019. https://www.pow ervault.co.uk/article/powervault-partners-with-octopus-energy-to-enhance-th e-benefits-of-smart-tariffs-and-smart-batteries-for-home-owners/.

[88] Committee on Climate Change (CCC). UK housing: fit for the future?. 2019.

[89] Committee on Climate Change (CCC). Reducing UK emissions: 2018 progress report to parliament. 2018

[90] Palmer J, Cooper I. United Kingdom housing energy fact file. DECC; 2013.

[91] Palmer J, Terry N, Kane T. Further analysis of the household electricity survey early findings: demand side management. DECC/Defra; 2013.

[92] Ofgem. The decarbonisation of heat (Ofgem's Future Insights Series). 2016.

[93] Hanna R, Parrish B, Gross R. Best practice in heat decarbonisation policy: A review of the international experience of policies to promote the uptake of lowcarbon heat supply. UKERC; 2016.

[94] Freedom Project. Freedom Project Final Report. Western Power Distribution/ Wales \& West Utilities; 2018.

[95] Carmichael R, Rhodes A, Hanna R, Gross R. Smart and flexible electric heat: an Energy Futures Lab briefing paper. Imperial College London; 2020. https://spiral. imperial.ac.uk:8443/handle/10044/1/82290.

[96] Advice Citizens. Early consumer experiences of smart meters. 2018.

[97] Smart Energy GB. Smart Energy GB Consumer engagement plan and budget. Smart Energy GB; 2018. 2017.

[98] Smart Energy GB. Wastage (Smart meter advert). Smart Energy GB; 2020. https ://www.youtube.com/watch? $v=0$ s8BdqXcoYM.

[99] Smart Energy GB. When will you get a smart meter? Your questions answered (Smart Meter advert). Smart Energy GB; 2020. https://www.youtube.com/watch ? $\mathrm{v}=$ CXa0Wa7WZfs.

[100] Smart Energy GB. Thank You (Smart meter ad). Smart Energy GB; 2019. https://www.youtube.com/watch?v=dH5YzTTsLvo.

[101] Smart Energy GB. I Want ... (Smart meter ad). Smart Energy GB; 2019. https://www.youtube.com/watch?v=9JxmFCo77-0.

[102] Buchanan K, Banks N, Preston I, Russo R. The British public's perception of the UK smart metering initiative: threats and opportunities. Energy Pol 2016;91: 87-97. https://doi.org/10.1016/j.enpol.2016.01.003.

[103] Shakoor AA, Davies G, Strbac G, Pudjianto D, Teng F, Papadaskalopoulos D, et al. Roadmap for Flexibility Services To 2030. Poyry/Imperial College London; 2017.

[104] Buryk S, Mead D, Mourato S, Torriti J. Investigating preferences for dynamic electricity tariffs: the effect of environmental and system benefit disclosure. Energy Pol 2015;80:190-5. https://doi.org/10.1016/j.enpol.2015.01.030.

[105] Energy and Climate Change Committee. Smart meter roll-out Fourth Report of Session 2013-14 The Energy and Climate Change Committee. 2013.

[106] SMMT. Record demand for alternatively fuelled cars in November but overall UK market falls -1.3\% 2019. https://www.smmt.co.uk/2019/12/record-demand-foralternatively-fuelled-cars-in-november-but-overall-uk-market-falls-1-3/.

[107] Committee on Climate Change (CCC). Reducing UK emissions: 2019 Progress Report to Parliament. 2019. London.

[108] Regen. Harnessing the electric vehicle revolution. Regen; 2018.

[109] Napp T, Bernie D, Thomas R, Lowe J, Hawkes A, Gambhir A. Exploring the feasibility of low-carbon scenarios using historical energy transitions analysis. Energies 2017;10. https://doi.org/10.3390/en10010116.

[110] HM Gov.. Tax benefits for ultra low emission vehicles. HM Gov.; 2017. https ://assets.publishing.service.gov.uk/government/uploads/system/uploads/atta chment data/file/709655/ultra-low-emission-vehicles-tax-benefits.pdf.

[111] Noel L, Zarazua de Rubens G, Kester J, Sovacool BK. Beyond emissions and economics: rethinking the co-benefits of electric vehicles (EVs) and vehicle-togrid (V2G). Transport Pol 2018;71:130-7. https://doi.org/10.1016/j. tranpol.2018.08.004.

[112] ClientEarth. ClientEarth's Climate Snapshot: A survey of UK attitudes towards climate change and its impacts. 2018.

[113] Zarazua de Rubens G, Noel L, Sovacool BK. Dismissive and deceptive car dealerships create barriers to electric vehicle adoption at the point of sale. Nat Energy 2018;3:501-7. https://doi.org/10.1038/s41560-018-0152-x.

[114] Science and Technology Committee. Clean Growth: Technologies for meeting the UK's emissions reduction targets. 2019.

[115] Palmer K, Tate JE, Wadud Z, Nellthorp J. Total cost of ownership and market share for hybrid and electric vehicles in the UK, US and Japan. Appl Energy 2018; 209:108-19. https://doi.org/10.1016/j.apenergy. 2017.10.089.

[116] Hardman S, Chandan A, Tal G, Turrentine T. The effectiveness of financial purchase incentives for battery electric vehicles - a review of the evidence. Renew Sustain Energy Rev 2017;80:1100-11.

[117] Energy Saving Trust. Electric Vehicle Loan 2020. https://energysavingtrust.org. uk/scotland/grants-loans/electric-vehicle-loan.

[118] Department for Transport. Vehicle Licensing Statistics. Annual 2018;2019.

[119] HM Treasury. Review of WLTP and vehicle taxes: A review into the impact of the Worldwide harmonised Light vehicles Test Procedure (WLTP) on Vehicle Excise Duty and company car tax. HM Gov; 2019. https://www.gov. uk/government/publications/review-of-wltp-and-vehicle-taxes\#history. [Accessed 26 February 2020].

[120] BEIS. Upgrading Our Energy System - Smart Systems and Flexibility Plan: Progress Update. BEIS; 2018. 
[121] European Parliament, Council of the EU. Directive (EU) 2019/944 on Common Rules for the Internal Market for Electricity and Amending Directive 2012/27/ EU. Off J Eur Union; 2019. http://eur-lex.europa.eu/pri/en/oj/dat/2003/1_28 5/1_28520031101en00330037.pdf.

[122] Morris M, Hardy J. Policy \& Regulatory Landscape Review Series - Working Paper 1: Electricity storage \& electric vehicles. Energy Revolution Research Centre, Strathclyde, UK. University of Strathclyde Publishing; 2019.

[123] UK Parliament. Value Added Tax (Reduced Rate) (Energy-Saving Materials) Order 2019 (SI 2019 No. 958) 2019;2019:1-22.

[124] Burke J, Byrnes R, Fankhauser S. How to price carbon to reach net-zero emissions in the UK. London: Grantham Research Institute on Climate Change and the Environment and Centre for Climate Change Economics and Policy, London School of Economics and Political Science.; 2019.

[125] Gissey GC, Guo B, Newbery D, Lipman G, Montoya L, Dodds P, et al. The value of international electricity trading, A project commissioned by Ofgem. 2019.

[126] Hirst N. Paying for net-zero - The fiscal framework for the UK's transition to lowcarbon energy. Grantham Institute, Imperial College London; 2020. https://doi. org/10.25561/78217.

[127] Delivering Ofgem. Faster and More Reliable Switching: proposed new switching arrangements. 2017.

[128] BEIS. Implementing Midata in the Domestic Energy Sector, Government response to the Call for Evidence. 2018.

[129] Ofgem. Moving to reliable next-day switching Target Operating Model and Delivery Approach. 2015.

[130] Citizens Advice. The Future of Digital Comparison Tools. Citizens Advice; 2017.

[131] CMA. DCTs market study: Paper D Making comparison easier and more effective. 2017.

[132] Which?. Digital Comparison Tools: Response to CMA's initial study. Which?; 2017.

[133] He X, Azevedo I, Meeus L. Shift, not drift: Towards active demand response and beyond. 2013.

[134] CMA. Energy Market Investigation: Price comparison websites. 2015.
[135] CMA Paper C. The application of the law and regulation to DCTs (Digital comparison tools market study Final report). 2017.

[136] theenergyst.com. Business energy supplier Squeaky calls out biomass as 'dirty', says consumers being misled. 2018. https://theenergyst.com/business-energy-s upplier-squeaky-calls-biomass-dirty-says-consumers-misled/.

[137] Energy Data Taskforce. A strategy for a Modern Digitalised Energy System. Energy Systems Catapult; 2019. https://es.catapult.org.uk/wp-content/uploads/ 2019/06/EDTF-A-Strategy-for-a-Modern-Digitalised-Energy-System-FINAL-REP ORT-1.pdf.

[138] Federation of Small Businesses (FSB).. Open Energy: Using Data to Create a Smarter, Cheaper and Fairer Energy Market. FSB; 2018.

[139] Hardy J, Sandys L, Green R. Reshaping Regulation: Normalising the energy sector. Presented at BIEE Conference, Oxford; Sept. 2018.

[140] Carmichael R. Behaviour change, public engagement and Net Zero, a report for the Committee on Climate Change. Imperial College London; 2019.

[141] Frerk M. Upping the ambition level for smart meter data. Sustainability First; 2018. https://www.sustainabilityfirst.org.uk/blog/upping-the-ambition-level-f or-smart-meter-data.

[142] Ofgem. Consumer views on sharing half-hourly settlement data. Ofgem 2018. htt ps://www.ofgem.gov.uk/system/files/docs/2018/07/consumer_views_on_shari ng_hhs_data_1.pdf.

[143] BIS. Review of the midata voluntary programme. 2014.

[144] Frerk M. Smart Meter Energy Data Public Interest Advisory Group (PIAG), Final Report - Phase 1. Sustainability First \& Centre for Sustainable Energy; 2019.

[145] Connolly D, Lund H, Mathiesen BV, Leahy M. A review of computer tools for analysing the integration of renewable energy into various energy systems. Appl Energy 2010;87:1059-82. https://doi.org/10.1016/j.apenergy.2009.09.026.

[146] National Grid. Modelling Methods (FES) Version 2.0 July 12th. National Grid; 2018.

[147] Ofgem.. Smart Meter Rollout: Open letter on Energy Suppliers' Progress, Future Plans and Regulatory Obligations. 2020. https://www.ofgem.gov.uk/system/ files/docs/2020/06/open_letter_2020_smart_rollout_progress_and_forward_look. pdf. 